\title{
The Prognostic Role of NEDD9 and P38 Protein Expression Levels in Urinary Bladder Transitional Cell Carcinoma
}

\author{
Ola A. Harb, ${ }^{1}$ Rasha Haggag, ${ }^{2}$ Maged M. Ali, ${ }^{3}$ Shereen El Shorbagy, ${ }^{2}$ Abeer M. Abdelbary, \\ Lobna A. Abdelaziz, ${ }^{4}$ Reham A. Salim, ${ }^{4}$ and Khaled M. Abdel Wahab ${ }^{3}$ \\ ${ }^{1}$ Department of Pathology, Faculty of Medicine, Zagazig University, Sharkia, Egypt \\ ${ }^{2}$ Department of Medical Oncology, Faculty of Medicine, Zagazig University, Sharkia, Egypt \\ ${ }^{3}$ Department of Urology, Faculty of Medicine, Zagazig University, Sharkia, Egypt \\ ${ }^{4}$ Department of Clinical Oncology and Nuclear Medicine, Faculty of Medicine, Zagazig University, Sharkia, Egypt
}

Correspondence should be addressed to Rasha Haggag; dr_rmmh@yahoo.com

Received 17 July 2016; Revised 15 October 2016; Accepted 18 October 2016; Published 17 January 2017

Academic Editor: Akira Hara

Copyright (C) 2017 Ola A. Harb et al. This is an open access article distributed under the Creative Commons Attribution License, which permits unrestricted use, distribution, and reproduction in any medium, provided the original work is properly cited.

\begin{abstract}
Background. The most common malignant tumor of the urinary bladder is transitional cell carcinoma (TCC). Neural precursor cell-expressed developmentally downregulated protein 9 (NEDD9) is found to be a cell adhesion mediator. P38 Mitogen-Activated Protein Kinase is a serine/threonine kinases member which can mediate carcinogenesis through intracellular signaling. Methods. To assess their prognostic role; NEDD9 and p38 protein were evaluated in sections from 50 paraffin blocks of TCC. Results. The high expressions of NEDD9 and p38 protein were significantly associated with grade, stage, distant metastasis $(p<0.001)$, number of tumors, lymph node metastasis, and tumor size $(p<0.001,0.002 ; 0.018,<0.001$; and $0.004,0.007$, respectively). High NEDD9 and $\mathrm{p} 38$ detection had a worse 3 -year OS ( $p=0.041$ and $<0.001$, respectively). By multivariate analysis the NEDD9 and p38 protein expression levels and various clinicopathological criteria including gender, grade, stage of the tumor, and regional lymph node involvement were independent prognostic parameters of TCC of the urinary bladder patients' outcome. Conclusion. NEDD9 and p38 protein expressions were poor prognostic markers of TCC.
\end{abstract}

\section{Introduction}

Bladder cancer is the 4th commonest malignancy worldwide and the 8th cause of cancer related mortality among males with men to women ratio of $3: 1$. In the United States, an estimated 74,690 new cases of bladder cancer and 15,580 deaths occurred in year 2014 [1].

In Egypt, bladder malignancies were the commonest among urinary system malignant tumors (90.71\%) and the third among all malignancies [2]. Most of patients with bladder carcinoma had 30\%-70\% recurrence rate and 10\%$30 \%$ of them may progress to muscle-invasive tumors [3]. Transitional cell carcinoma (TCC) forms more than $90 \%$ of all cases of malignancies of the urinary bladder [4], and detection of biomarkers, molecular mechanisms, and new immunohistochemical markers are helpful in expecting its evolution. NEDD9 (neural precursor cell-expressed developmentally downregulated protein 9) also known as HEF1 (human enhancer of filamentation 1) is a cytoskeletal protein which is considered a signaling mediator of various cellular events including cell adhesion, cell cycle regulation, apoptosis, and tumorigenesis [5].

p38 MAPK (Mitogen-Activated Protein Kinase) is a class of serine/threonine kinases that mediate intracellular signaling associated with a variety of cellular activities including cell proliferation, differentiation, survival, death, and transformation [6].

As previous studies implicated that NEDD9 and p38 protein have a promoting effect in the carcinogenic process in many other organs, however, the prognostic value of studying the expression of both of them in urinary bladder transitional cell carcinoma has not been investigated yet, so we have chosen such markers. 
In this study we aimed to assess the expression of NEDD9 and $\mathrm{p} 38$ protein and detect their prognostic role in urinary bladder TCC.

\section{Patients and Methods}

This retrospective cohort study was conducted at Pathology, Urology, and Medical Oncology and Clinical Oncology and Nuclear Medicine Departments, Faculty of Medicine, Zagazig University. Archival formalin fixed paraffin-embedded 50 tissue blocks derived from 50 cases each block taken from one patient of transitional cell carcinoma of the urinary bladder were collected from patients previously undergone transurethral bladder resection (TUR) between November 2012 and November 2015.

This study complied with the guidelines of the local ethics committee and was approved by the Zagazig University IRB.

The TNM staging system was used for pathologic staging [7], and the World Health Organization classification was used for pathologic grading of bladder TCC [8]. Each tumor was reevaluated by retrospective examination of the medical records and the slide file of the Pathology Department, sex, age, tumor size, histological subtype, grade, depth of muscle invasion, status of lymph node metastasis, and distant metastasis.

2.1. Immunohistochemical Staining. Immunohistochemical staining was carried out using the streptavidin-biotin immunoperoxidase technique [9]. $4 \mu \mathrm{m}$ thick sections were cut from formalin fixed paraffin-embedded blocks, put on positively charged slides, deparaffinized in xylene, and rehydrated in graded alcohol. Sections were boiled in citrate buffer ( $\mathrm{pH}$ 6.0) for $20 \mathrm{~min}$ and then washed in phosphate buffer saline ( $\mathrm{pH} 7.3$ ).

We have used 3\% hydrogen peroxide in methanol to overcome endogenous peroxidase activity, followed by incubation with $1 \%$ bovine serum albumin to reduce background nonspecific binding.

Then the slides were incubated overnight with mouse monoclonal anti-NEDD9 antibody (NEDD9 clone ab18056, dilution 1: 100 Abcam, Cambridge, UK) and rabbit polyclonal anti-p38 protein antibody (clone ab197348) dilution 1:100 Abcam, Cambridge, UK, at $41 \mathrm{C}$ in a humid chamber. A biotin-labeled secondary antibody was added for $15 \mathrm{~min}$, followed by horseradish peroxidase for $15 \mathrm{~min}$. Tissues were then stained for $5 \mathrm{~min}$ with diaminobenzidine tetrahydrochloride (DAB) and counterstained with hematoxylin.

Pancreatic adenocarcinoma was used as positive control for NEDD9 [10] while colon adenocarcinoma was used for p38 protein. Negative controls were performed by omitting of the primary antibody and replacement with phosphate buffered saline.

2.2. Evaluation of Immunostaining of Both Markers in TCC Cells. NEDD9 was cytoplasmic, nonspecific membranous staining and may be detected but we depend in our scoring only on cytoplasmic immunoexpression, and P38 was nuclear.
We have reviewed and scored the degree of immunostaining based on the intensity of staining and the percentage of immunoreactive cells.

We defined low and high expression by the following steps:

(1) Staining intensity was graded according to the following criteria: 0 (no staining); 1 (weak staining = light yellow); 2 (moderate staining = yellowish brown); and 3 (strong staining $=$ brown).

(2) The extent of immune-reactivity was graded as follows: 0 , positive cells less than $1 \%$; (1) $2 \%-25 \%$; (2) 26\%-50\%; (3) 51\%-75\%; (4) more than $75 \%$.

(3) The total score was calculated by multiplying the intensity and extent, and the samples were divided into four categories according to the following grades: 0-1 (-); 2-4 (+); 5-8 (++); and 9-12 (+++).

(4) An optimal cut-off value was identified as follows: a staining index score of more than 4 was used to define tumors with high HEF1 expression, and a staining index score less than/or equal to 4 was used to indicate low HEF1 expression.

The expression of both of our markers was uniform across the tissue section and we calculate the intensity and extent of stain semiquantitatively in the maximum areas of expression ([11, 12]; Figures 1 and 2).

2.3. Statistical Analysis. All statistics were performed using SPSS 22.0 for windows (SPSS Inc., Chicago, IL, USA) and MedCalc windows (MedCalc Software bvba 13, Ostend, Belgium). Strength of relationship between NEDD9, p38, and clinicopathological features was determined by computing appropriate correlation coefficient (Spearman's). KaplanMeier method was used to estimate survival curves and comparison between groups was done by long-rank test. A $p$ value $<0.05$ was considered statistically significant. Multivariate analyses were done using the Cox proportional hazards regression model (Table 5).

\section{Results}

Fifty patients, 35 males and 15 females, were enrolled in this study, with age ranging from 35 to 75 years (mean \pm SD: $55.08 \pm 10.36)$, Table 1 .

NEDD9 expression and its correlation clinicopathological features are as follows:

(i) The expression of HEF1 in TCC of the bladder was significantly associated with number of tumors, depth of muscle invasion, grade and stage, and distant metastasis $(p<0.001)$, lymph node metastasis $(p=$ $0.018)$, and tumor size $(p=0.004)$, but it had no association with age (Table 1; Figure 1).

P38 protein expression and its correlation clinicopathological features are as follows:

(i) The expression of p38 MAPK in TCC of the bladder was significantly associated with depth of muscle 


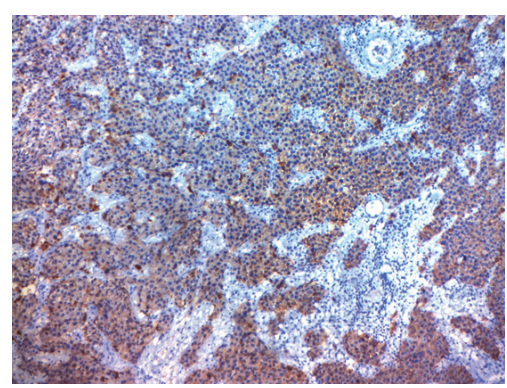

(a)

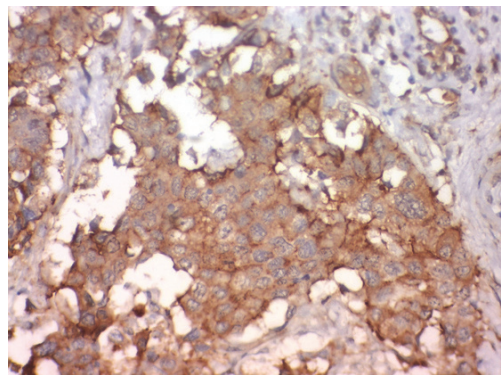

(d)

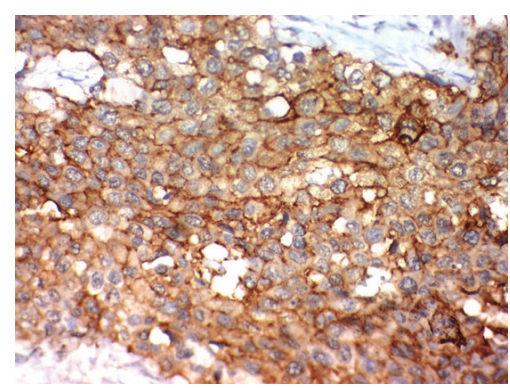

(b)

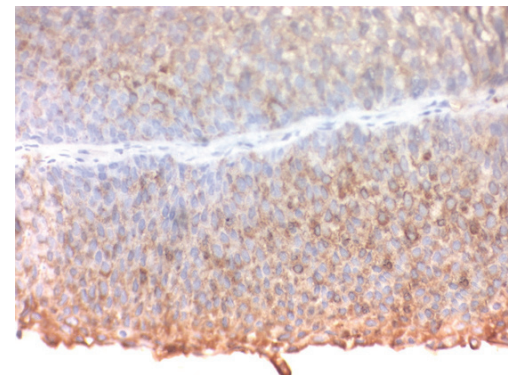

(e)

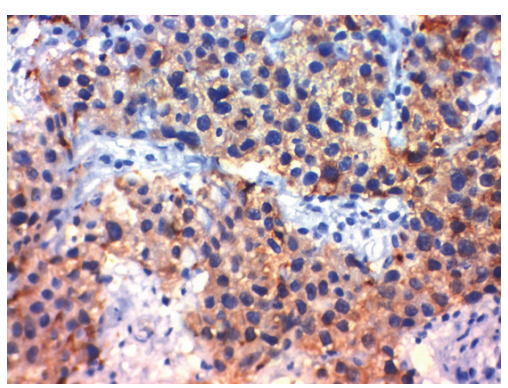

(c)

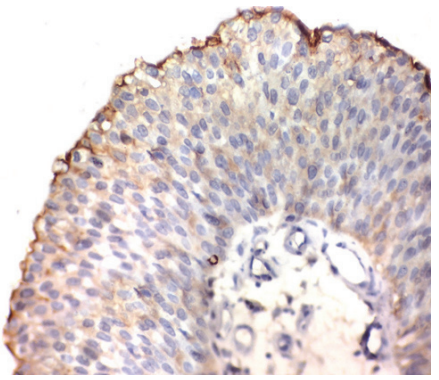

(f)

FIGURE 1: Immunohistochemical staining of NEDD9 in transitional cell carcinoma. Notes. (a)-(d) High NEDD9 immunohistochemical expression (in the cytoplasm) in muscle-invasive high grade transitional cell carcinoma of the urinary bladder ( $\uparrow$ ). (e)-(f) Low NEDD9 immunohistochemical expression in non-muscle-invasive low grade transitional cell carcinoma of the urinary bladder a $(\uparrow)$. Magnification: (a) the original magnification was $\times 100$ and (b)-(f) the original magnification was $\times 400$. NEDD9, neural precursor cell-expressed developmentally downregulated protein 9; TCC, transitional cell carcinoma.

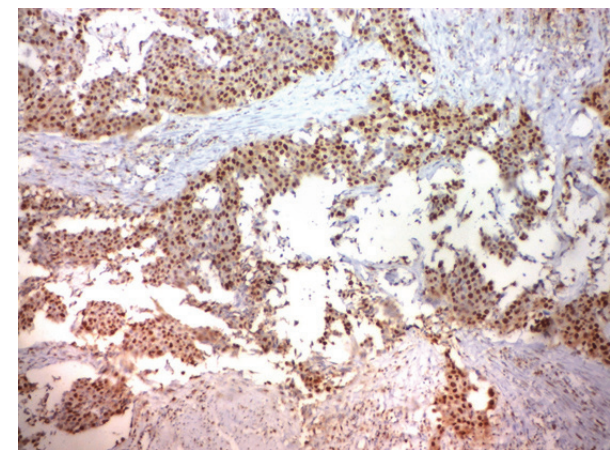

(a)

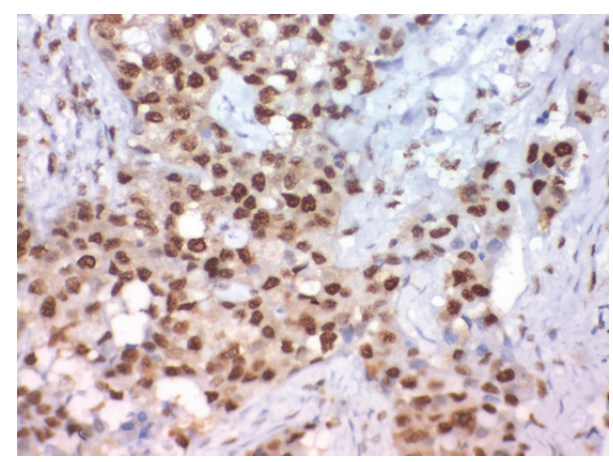

(c)

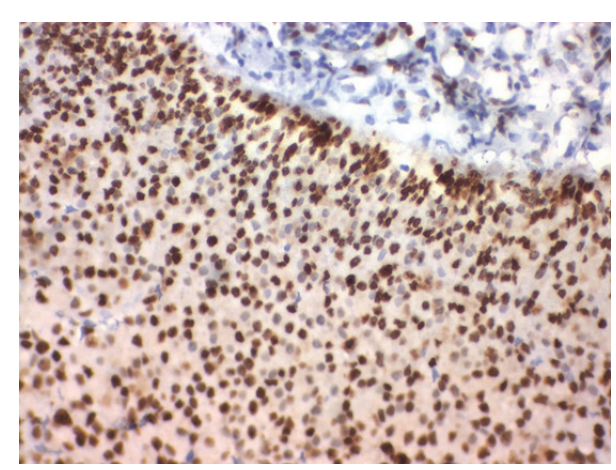

(b)

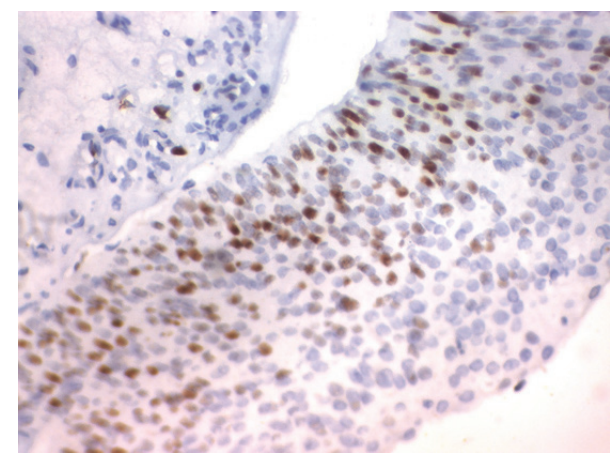

(d)

FIGURE 2: Immunohistochemical staining of P38 in transitional cell carcinoma. Notes. (a)-(b) High P38 immunohistochemical expression (in the nucleus) in muscle-invasive high grade transitional cell carcinoma of the urinary bladder $(\uparrow)$. Magnification: the original magnification was $\times 400$. (c)-(d) Low P38 immunohistochemical expression in non-muscle-invasive low grade transitional cell carcinoma of the urinary bladder ( $\uparrow$ ). Magnification: (a) the original magnification was $\times 100$. (b)-(d) The original magnification was $\times 400$. 


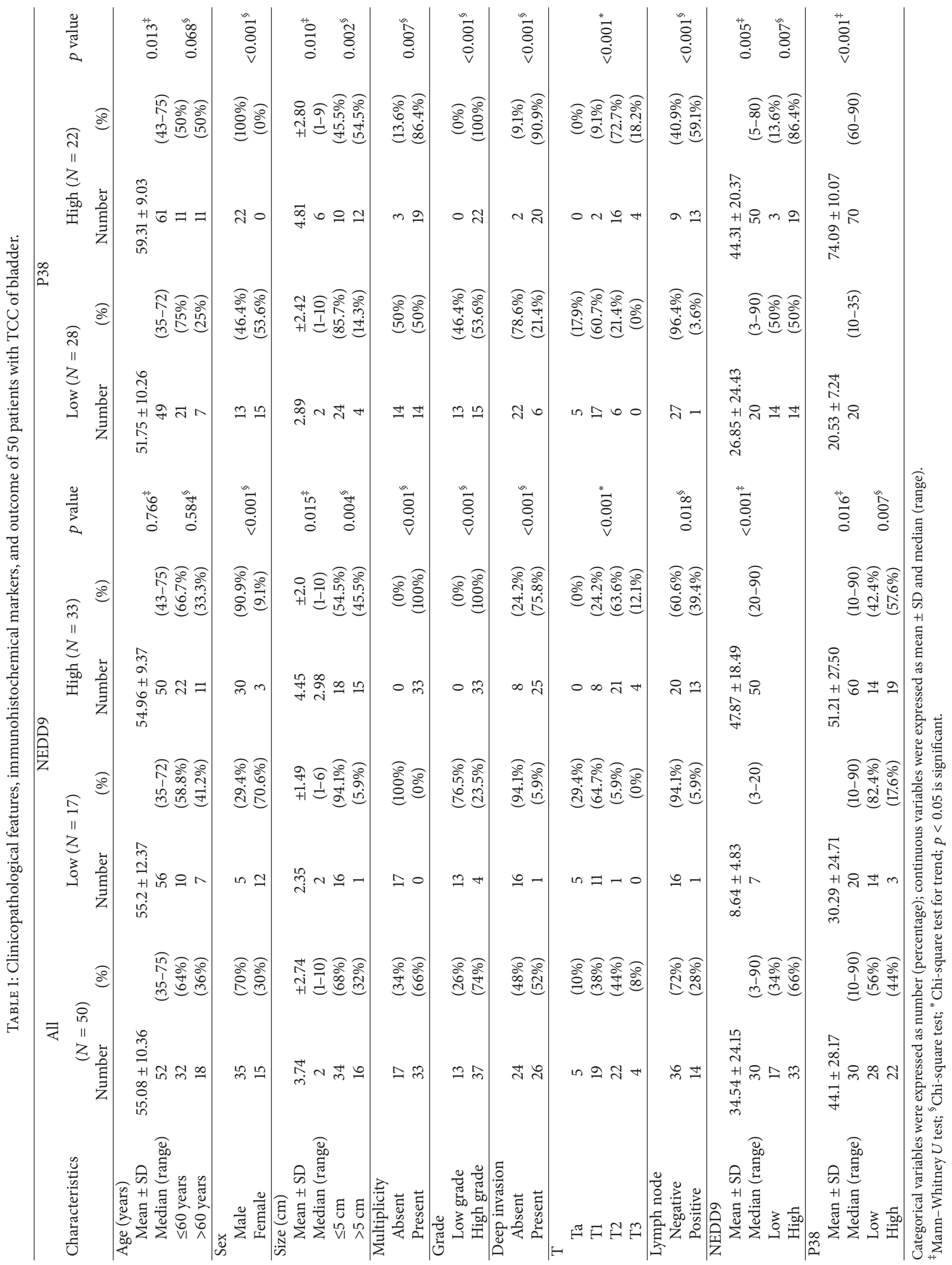




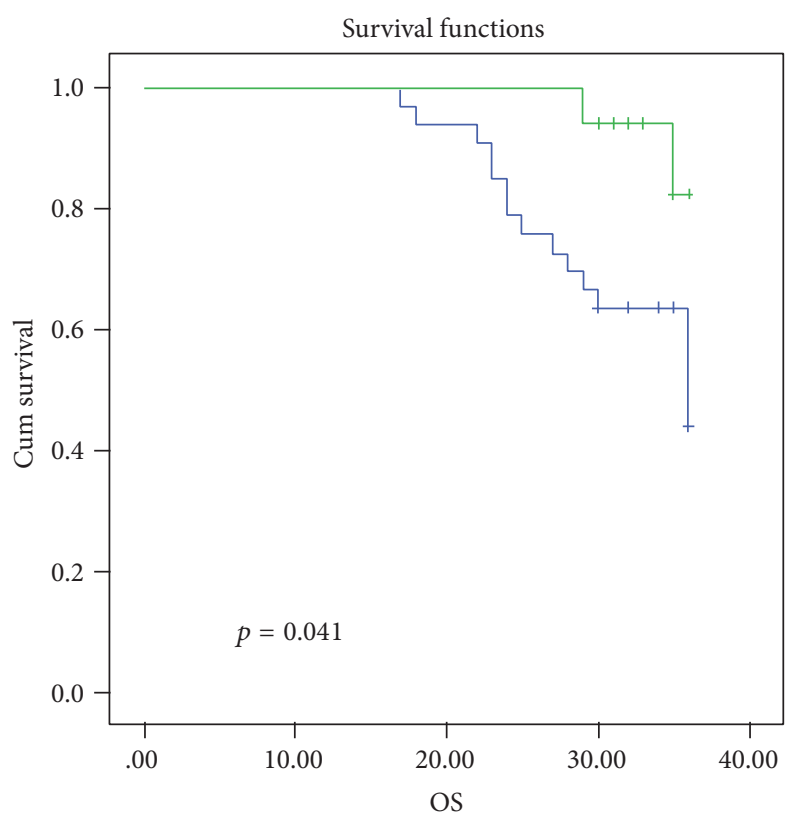

NEDD9 level

$\begin{array}{ll}\neg \mathrm{H} & + \text { H-censored } \\ \neg \mathrm{L} & + \text { L-censored }\end{array}$

(a)

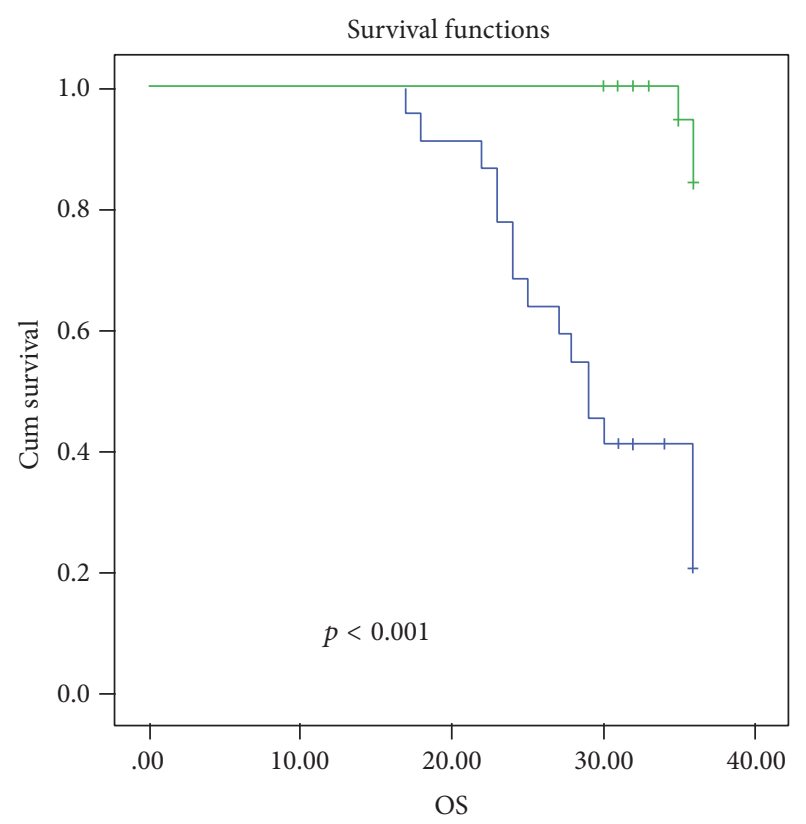

P38

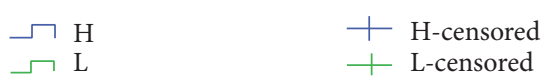

(b)

FIGURE 3: Kaplan-Meier plot of overall survival: (a) stratified according to NEDD9 and (b) stratified according to P38 protein expression.

invasion, grade, stage, lymph node metastasis, distant metastasis $(p<0.001)$, size $(p=0.007)$, and number of tumors $(p=0.002)$, but it had no association with age (Table 1: Figure 2).

(ii) The expression of both NEDD9 and p38 was significantly positively correlated with each other $r=$ $+0.460(p<0.001)$.

(iii) The sensitivity of combination of both NEDD9 and p38 as a predictor for deep muscle invasion of TCC of the bladder was $73.1 \%$ and the specificity is $100 \%$.

Survival Analysis. The 3-year OS rate was 52\% for all patients, $44.1 \%$ and $82.4 \%$ for high and low NEDD9 expression, respectively, and $20.5 \%$ and $82.4 \%$ in high and low p38 protein expression, respectively, and the 3-year OS rate is inversely related to high NEDD9 immunoreactivity and high P38 protein expression ( $p=0.041$ and $<0.001$, resp.; Table 2 ).

The 3 -year DFS rate was $65.6 \%$ for all patients, $47.6 \%$ and $100 \%$ in high and low NEDD9 expression, respectively, and $31.2 \%$ and $92.7 \%$ in high and low p38 protein expression, respectively, and highly significant inverse relationship was found between 3-year DFS and both high NEDD9 protein expression and high $\mathrm{p} 38$ protein expression $(p<0.001$; Table 3; Figures 3 and 4).

Overall survival Kaplan-Meier plot using both p38 MAPK and NEDD9 together to see if better patient stratification is possible showed that patients with high p38 MAPK expression had mean OS of $28.526 \pm 1.538$ versus $31 \pm$ 0.816 months in patients with high and low NEDD9 protein expression, respectively, while patients with low p38 MAPK expression had mean OS of $35.875 \pm 0.0$ versus $35.944 \pm$ 0.11 months in patients with high and low NEDD9 protein expression, respectively ( $p=0.46$; Figure 5).

By multivariate analysis NEDD9 and p38 protein expression levels and various clinicopathological features (gender, stage, grade, number of tumors, and regional lymph node involvement) were independent prognostic parameters of bladder cancer patients' outcome (Table 4).

\section{Discussion}

We found that the detection of NEDD9 in TCC of the bladder was significantly positively correlated with number of tumors, invasion depth, grade and stage, distant metastasis $(p<0.001)$, lymph node metastasis $(p=0.018)$, and tumor size $(p=0.004)$. Regarding outcome of our patients we found that the detection of NEDD9 in TCC of the bladder was significantly positively correlated with shortened progression-free survival (OS and DMFS) rates $(p=0.041)$. Our results indicate that NEDD9 is involved in the growth and progression of TCC and it may be an important biological marker for its invasion and metastasis. That was consistent with results of previous studies about TCC of the urinary bladder [13] and cancers of other organs such as stomach [14], lung [15], glioblastoma [16], melanoma, [17], and breast [18]. We found that NEDD9 expression is related to an aggressive behavior in TCC. Liu et al., 2014, proved that. That was explained by several mechanisms as it supports the activation of oncogenic signaling pathways in breast cancer 


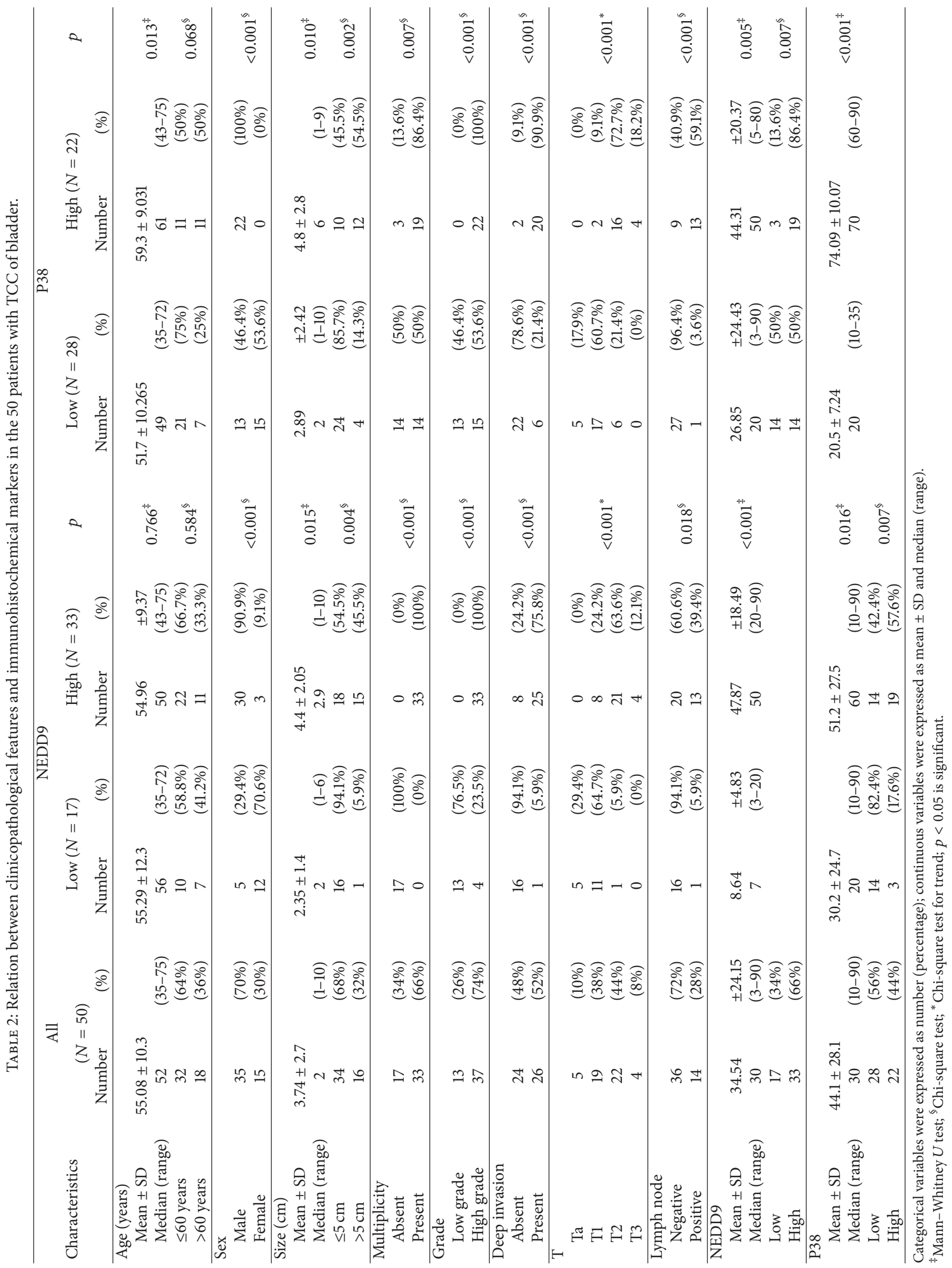


TABLE 3: Association and correlation between NEDD9, P38, and clinicopathological parameters in 50 patients with TCC of bladder.

\begin{tabular}{lcccccccc}
\hline & \multicolumn{2}{c}{ NEDD9 (\%) } & \multicolumn{2}{c}{ NEDD9 } & \multicolumn{2}{c}{ P38 (\%) } & \multicolumn{2}{c}{ P38 } \\
& $r$ & $p$ value & $r$ & $p$ value & $r$ & $p$ value & $p$ value \\
\hline Age & +0.152 & 0.293 & -0.015 & 0.918 & +0.448 & 0.001 & +0.366 \\
Sex & -0.392 & 0.005 & -0.636 & $<0.001$ & -0.428 & $<0.001$ & -0.580 & $<0.001$ \\
Size & +0.601 & $<0.001$ & +0.366 & 0.009 & +0.498 & $<0.001$ & +0.352 & 0.012 \\
Multiplicity & +0.816 & $<0.001$ & +0.707 & $<0.001$ & +0.300 & 0.011 & +0.356 & 0.007 \\
Grade & +0.665 & $<0.001$ & +0.826 & $<0.001$ & +0.441 & $<0.001$ & +0.465 & $<0.001$ \\
Deep invasion & +0.630 & $<0.001$ & +0.552 & $<0.001$ & +0.535 & $<0.001$ & 0.568 & $<0.001$ \\
T & +0.626 & $<0.001$ & +0.698 & $<0.001$ & +0.526 & $<0.001$ & +0.739 & $<0.001$ \\
Lymph node & +0.346 & 0.014 & +0.354 & 0.012 & +0.461 & $<0.001$ & +0.614 & $<0.001$ \\
NEDD9 (\%) & - & - & - & - & +0.460 & 0.001 & +0.362 & 0.010 \\
NEDD9 & - & - & - & - & +0.300 & 0.011 & +0.381 \\
P38 (\%) & +0.460 & 0.001 & +0.300 & 0.011 & - & - & - & - \\
P38 & +0.362 & 0.010 & +0.381 & 0.007 & - & - & - \\
\hline
\end{tabular}

$r$ correlation coefficient; $p<0.05$ is significant.

TABLE 4: Diagnostic performance of immunohistochemical markers as a predictor for deep invasion of TCC.

\begin{tabular}{|c|c|c|c|c|c|c|c|c|c|}
\hline Markers & $\begin{array}{c}\text { TP } \\
\text { No }(\%)\end{array}$ & $\begin{array}{c}\text { FP } \\
\text { No }(\%)\end{array}$ & $\begin{array}{c}\text { TN } \\
\text { No }(\%)\end{array}$ & $\begin{array}{c}\text { FN } \\
\text { No (\%) }\end{array}$ & $\begin{array}{c}\text { SN\% } \\
(95 \% \text { CI })\end{array}$ & $\begin{array}{c}\mathrm{SP} \% \\
(95 \% \mathrm{CI})\end{array}$ & $\begin{array}{c}\text { PPV\% } \\
(95 \% \mathrm{CI})\end{array}$ & $\begin{array}{l}\text { NPV\% } \\
(95 \% \text { CI })\end{array}$ & $\begin{array}{r}\text { Accuracy } \\
(95 \% \text { CI })\end{array}$ \\
\hline NEDD9 & $25(50 \%)$ & $8(16 \%)$ & $16(32 \%)$ & $1(2 \%)$ & $\begin{array}{c}96.2 \% \\
(88.8-100)\end{array}$ & $\begin{array}{c}66.7 \% \\
(47.8-85.5)\end{array}$ & $\begin{array}{c}75.8 \% \\
(61.1-90.4)\end{array}$ & $\begin{array}{c}94.1 \% \\
(82.9-100)\end{array}$ & $\begin{array}{c}82 \% \\
(71.4-92.6)\end{array}$ \\
\hline P38 & $20(40 \%)$ & $2(4 \%)$ & $22(44 \%)$ & $6(12 \%)$ & $\begin{array}{c}76.9 \% \\
(60.7-93.1)\end{array}$ & $\begin{array}{c}91.7 \% \\
(80.6-100)\end{array}$ & $\begin{array}{c}90.9 \% \\
(78.9-100)\end{array}$ & $\begin{array}{c}78.6 \% \\
(63.4-93.8)\end{array}$ & $\begin{array}{c}84 \% \\
(73.8-94.2)\end{array}$ \\
\hline $\begin{array}{l}\text { NEDD9 \& } \\
\text { P38 }\end{array}$ & $19(38 \%)$ & $0(0 \%)$ & $27(52 \%)$ & $7(14 \%)$ & $\begin{array}{c}73.1 \% \\
(56-90.1)\end{array}$ & $100 \%$ & $100 \%$ & $\begin{array}{c}79.4 \% \\
(65.8-93)\end{array}$ & $\begin{array}{c}86 \% \\
(76.7-95.3)\end{array}$ \\
\hline
\end{tabular}

TP: true positive; FP: false positive; TN: true negative; FN: false negative; SN: sensitivity; SP: specificity; PPV: positive predictive value; NPV: negative predictive value, $95 \%$ CI: $95 \%$ confidence interval; $p<0.05$ is significant.

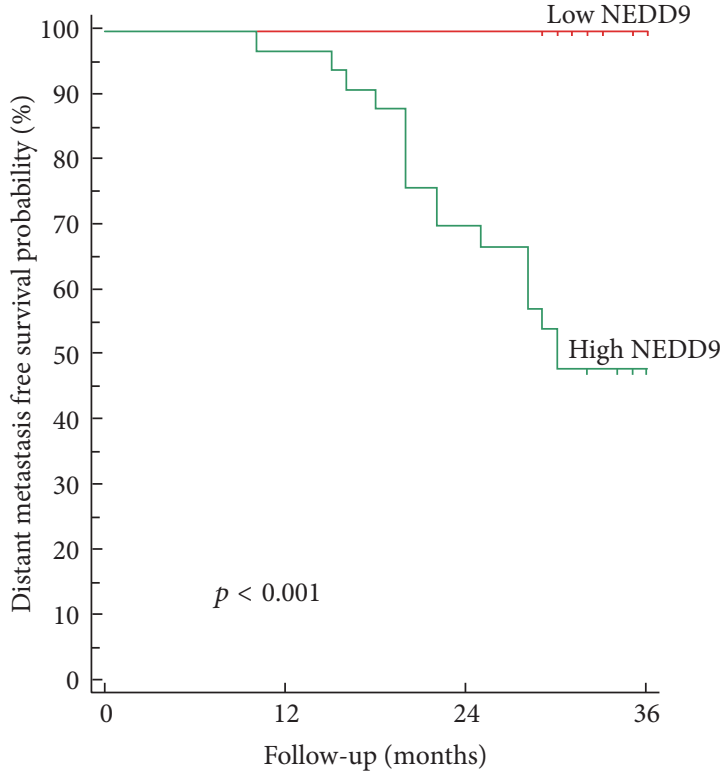

(a)

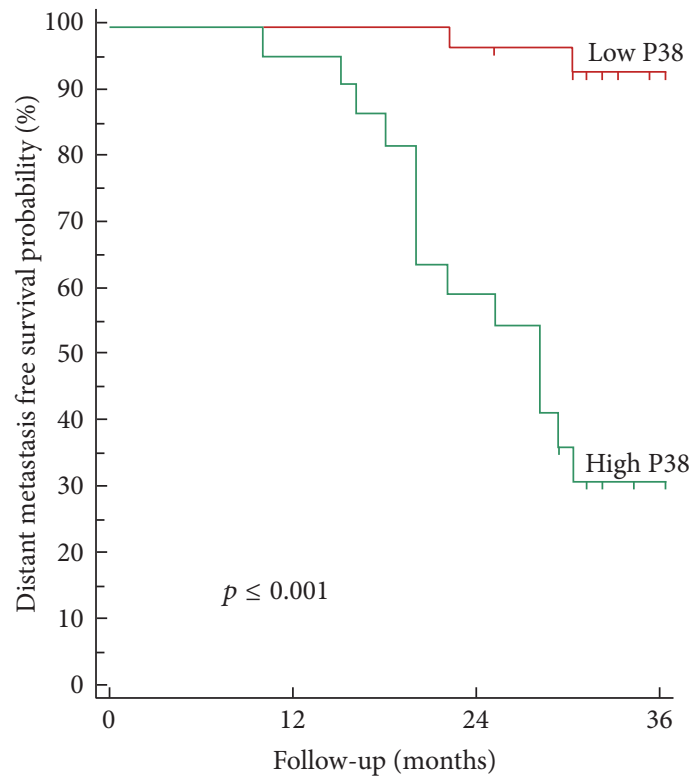

(b)

FIGURE 4: Kaplan-Meier plot of disease free survival: (a) stratified according to NEDD9 and (b) stratified according to P38 protein expression. 
TABLE 5: Multivariate analyses for overall survival by Cox regression model.

\begin{tabular}{|c|c|c|c|c|}
\hline Variable & Parameters & Hazard ratio & $95 \% \mathrm{CI}$ & $p$ value \\
\hline Age (years) & $\leq 60$ versus $>60$ & 0.83 & $0.322-2.175$ & 0.7 \\
\hline Gender & Male versus female & 0.34 & $0.129-0.972$ & 0.006 \\
\hline Stage & $\geq \mathrm{T} 2$ versus $\mathrm{Ta}-\mathrm{T} 1$ & 9.8 & $2.25-42.88$ & $<0.001$ \\
\hline Grade & G3 versus G1/2 & 2.49 & $0.9-6.84$ & 0.02 \\
\hline Number of tumors & Multiple versus single & 0.49 & $0.3-1.09$ & 0.02 \\
\hline Regional lymph node involvement & Present versus absent & 0.02 & $0.0-4.795$ & $<0.001$ \\
\hline NEDD9 & Low versus high & 2.01 & $0.95-4.22$ & 0.029 \\
\hline P38 & Low versus high & 3.7 & $1.81-7.94$ & $<0.001$ \\
\hline
\end{tabular}

$p<0.05$ is significant.

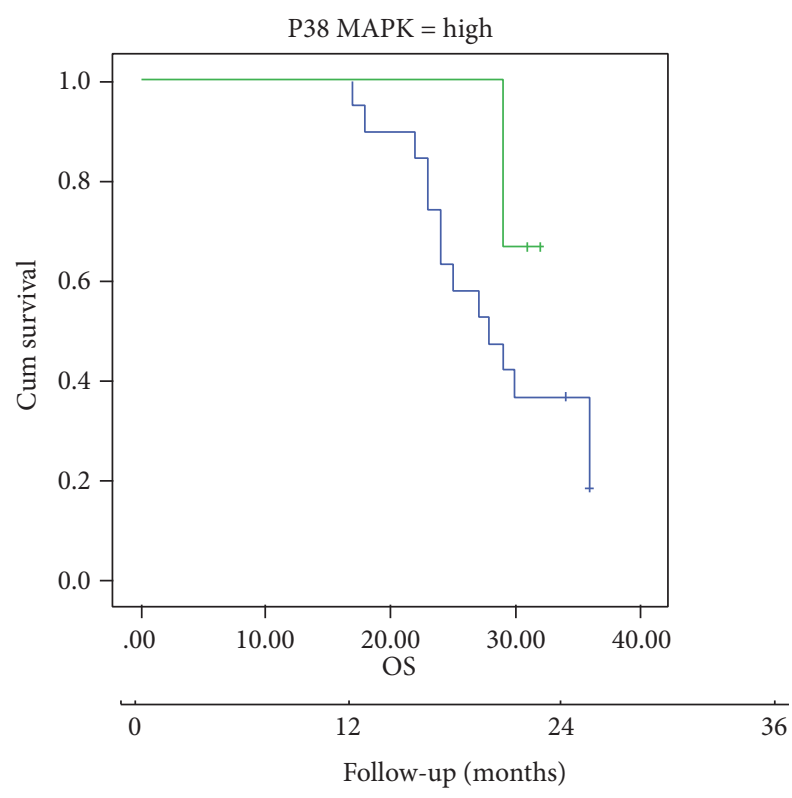

NEDD9 level

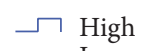

$\neg$ Low
+ High-censored

(a)

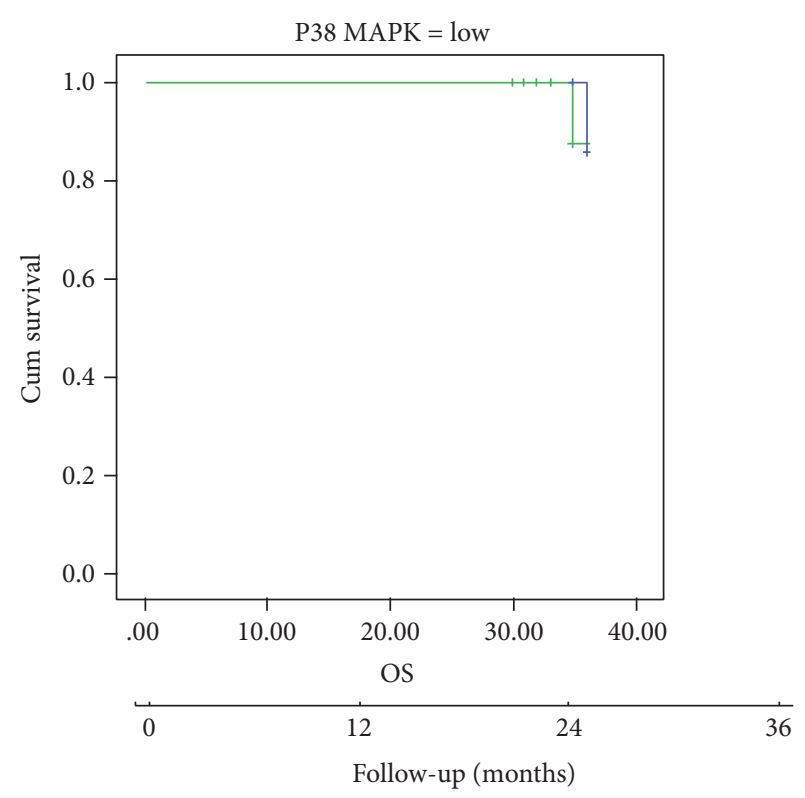

NEDD9 level

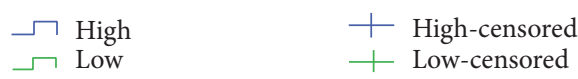

(b)

FIGURE 5: Overall survival Kaplan-Meier plot using both p38 MAPK and NEDD9 together.

development. In colorectal malignancy, NEDD9, a novel target of Wnt signaling, and its high expression increased colonic cell invasion [19].

We proved that the expression of $\mathrm{p} 38$ protein in TCC of the bladder was significantly positively related to poor prognosis and progression and was significantly associated with shortened progression-free survival (OS and DMFS), $p<0.001$. That was similar to results of previous studies as NEDD9 regulates MMP-2 and MMP-9 expression in TCC of the bladder cells that increase its invasion and metastases [20]. Our results were similar to the results of Thomas et al., 2014, who proved that also activation of p38 protein is associated with disease progression in head and neck squamous cell carcinoma [21]. Our findings were in agreement with researches that found that increased levels of activated p38 protein have been correlated with aggressive behavior of leukemia, breast, prostate, gastric cancers, and follicular lymphoma [22]. Activation of Cas-family proteins had been incriminated as signaling molecules in cellular motility, apoptosis, and oncogenic transformation. HEF1/Cas-L (NEDD9) is a Cas-family member whose production is important to increase levels of mRNA transcripts that encode proteins that are associated with motility, cell conversion, and invasiveness. Upregulation of such proteins suggests mechanisms through which misregulation of NEDD9 may be involved in cancer progression. Our work has proved the axis that links Casfamily protein (NEDD9/Cas-L) to the activation of p38 protein signaling pathway and that was in agreement Law et al., who found that NEDD9 overproduction results in activation of $\mathrm{p} 38$ protein, as NEDD9 rapidly induces changes in cellular morphology and motility, enhancing cell speed and haptotaxis towards fibronectin in a process partially dependent on intact p38 protein signaling pathway [23]. Law et al., 2000, stated that p38 kinase is activated by NEDD9 [23] 
and that activation of p38 kinase has also been implicated in cellular mobility [24].

The previous studies explained our finding of a significant positive correlation between the expression of NEDD9 and p38 protein $(p=0.007)$, indicating that there are synergistic effects between them during the development of invasion and metastases of transitional cell carcinoma of the urinary bladder; also their pattern and intensity of expression together can help to detect the prognosis of transitional cell carcinoma and predict patient outcome and survival.

\section{Conclusion}

NEDD9 and p38 protein may represent new prognostic molecular markers of TCC of the urinary bladder in relation to other markers.

\section{Competing Interests}

Conflict of interests relevant to this article was not reported.

\section{References}

[1] R. Siegel, J. Ma, Z. Zou, and A. Jemal, "Cancer statistics, 2014," CA Cancer Journal for Clinicians, vol. 64, no. 1, pp. 9-29, 2014.

[2] N. Mokhtar, I. Gouda, and I. Adel, "Cancer Pathology Registry 2003-2004 and time trend analysis," Journal of the Egyptian National Cancer Institute, vol. 19, no. 2, pp. 158-162, 2007.

[3] G. Dalbagni and H. W. Herr, "Current use and questions concerning intravesical bladder cancer group for superficial bladder cancer," Urologic Clinics of North America, vol. 27, no. 1, pp. 137-146, 2000.

[4] P. Kapur, Y. Lotan, E. King et al., "Primary adenocarcinoma of the urinary bladder: value of cell cycle biomarkers," American Journal of Clinical Pathology, vol. 135, no. 6, pp. 822-830, 2011.

[5] Y. Wang, L. Bi, H. Wang et al., "NEDD9 rs760678 polymorphism and the risk of Alzheimer's disease: a meta-analysis," Neuroscience Letters, vol. 527, no. 2, pp. 121-125, 2012.

[6] A. Cuadrado and A. R. Nebreda, "Mechanisms and functions of p38 MAPK signalling," Biochemical Journal, vol. 429, no. 3, pp. 403-417, 2010.

[7] L. Sobin and C. Wittekind, TNM Classification of Malignant Tumours, Wiley-Liss, New York, NY, USA, 2002.

[8] J. N. Eble, G. Sauter, J. I. Epstein, and I. A. Sesterhenn, World Health Organization Classification of Tumours: Pathology and Genetics of Tumours of the Urinary System and Male Genital Organs, ARC Press, Lyon, France, 2004.

[9] S. M. Hsu, L. Raine, and H. Fanger, "Use of Avidin-BiotinPeroxidase Complex $(\mathrm{ABC})$ in immunoperoxidase techniques: a comparison between $\mathrm{ABC}$ and unlabeled antibody (PAP) procedures," Journal of Histochemistry and Cytochemistry, vol. 29, no. 4, pp. 577-580, 1981.

[10] M. Natarajan, J. E. Stewart Jr., E. A. Golemis et al., "HEF1 is a necessary and specific downstream effector of FAK that promotes the migration of glioblastoma cells," Oncogene, vol. 25, no. 12, pp. 1721-1732, 2006.

[11] Y. Li, J. H. Bavarva, Z. Wang et al., "HEF1, a novel target of Wnt signaling, promotes colonic cell migration and cancer progression," Oncogene, vol. 30, no. 23, pp. 2633-2643, 2011.
[12] A. A. Molinolo, S. M. Hewitt, P. Amornphimoltham et al., "Dissecting the Akt/mammalian target of rapamycin signaling network: emerging results from the head and neck cancer tissue array initiative," Clinical Cancer Research, vol. 13, no. 17, pp. 4964-4973, 2007.

[13] Q. Zhang, H.-J. Wang, D.-H. Zhang, G.-Q. Ru, X.-J. He, and Y.-Y. Ma, "High expression of HEF1 is associated with poor prognosis in urinary bladder carcinoma," OncoTargets and Therapy, vol. 7, pp. 1319-1326, 2014.

[14] R. Shi, L. Wang, T. Wang, J. Xu, F. Wang, and M. Xu, "NEDD9 overexpression correlates with the progression and prognosis in gastric carcinoma," Medical Oncology, vol. 31, no. 3, article 852, 2014.

[15] S. Kondo, S. Iwata, T. Yamada et al., "Impact of the integrin signaling adaptor protein NEDD9 on prognosis and metastatic behavior of human lung cancer," Clinical Cancer Research, vol. 18, no. 22, pp. 6326-6338, 2012.

[16] M. C. Speranza, V. Frattini, F. Pisati et al., "NEDD9, a novel target of miR-145, increases the invasiveness of glioblastoma," Oncotarget, vol. 3, no. 7, pp. 723-734, 2012.

[17] M. Kim, J. D. Gans, C. Nogueira et al., "Comparative oncogenomics identifies NEDD9 as a melanoma metastasis gene," Cell, vol. 125, no. 7, pp. 1269-1281, 2006.

[18] P. Bradbury, M. Mahmassani, J. Zhong et al., "PP2A phosphatase suppresses function of the mesenchymal invasion regulator NEDD9," Biochimica et Biophysica Acta-Molecular Cell Research, vol. 1823, no. 2, pp. 290-297, 2012.

[19] Y. Liu, D. Wang, K.-L. Zhao et al., "NEDD9 overexpression correlates with poor prognosis in gastric cancer," Tumor Biology, vol. 35, no. 7, pp. 6351-6356, 2014.

[20] B. Kumar, J. Sinclair, L. Khandrika, S. Koul, S. Wilson, and H. K. Koul, "Differential effects of MAPKs signaling on the growth of invasive bladder cancer cells," International Journal of Oncology, vol. 34, no. 6, pp. 1557-1564, 2009.

[21] B. Thomas, M. Stedman, and L. Davies, "Grade as a prognostic factor in oral squamous cell carcinoma: a population-based analysis of the data," The Laryngoscope, vol. 124, no. 3, pp. 688694, 2014.

[22] H. K. Koul, M. Pal, and S. Koul, "Role of p38 MAP kinase signal transduction in solid tumors," Genes and Cancer, vol. 4, no. 9-10, pp. 342-359, 2013.

[23] S. F. Law, G. M. O’Neill, S. J. Fashena, M. B. Einarson, and E. A. Golemis, "The docking protein HEF1 is an apoptotic mediator at focal adhesion sites," Molecular and Cellular Biology, vol. 20, no. 14, pp. 5184-5195, 2000.

[24] T. Matsumoto, K. Yokote, K. Tamura et al., "Platelet-derived growth factor activates p38 mitogen-activated protein kinase through a Ras-dependent pathway that is important for actin reorganization and cell migration," Journal of Biological Chemistry, vol. 274, no. 20, pp. 13954-13960, 1999. 


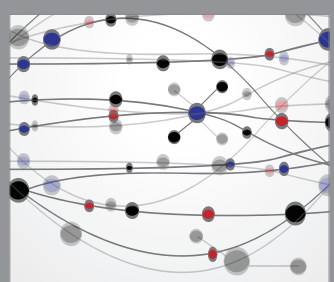

The Scientific World Journal
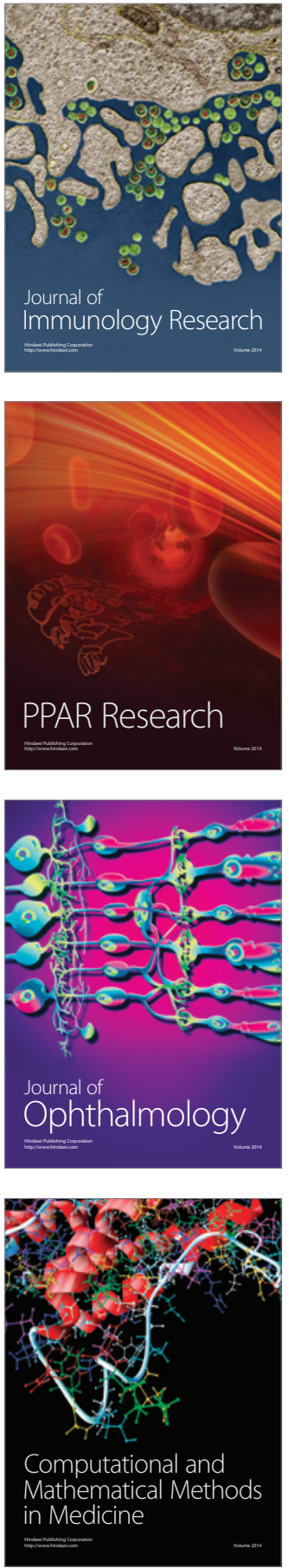

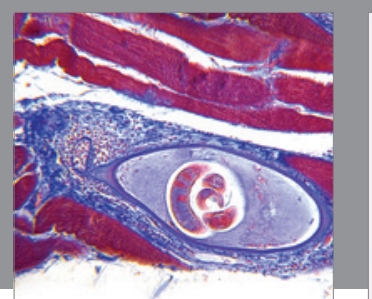

Gastroenterology Research and Practice
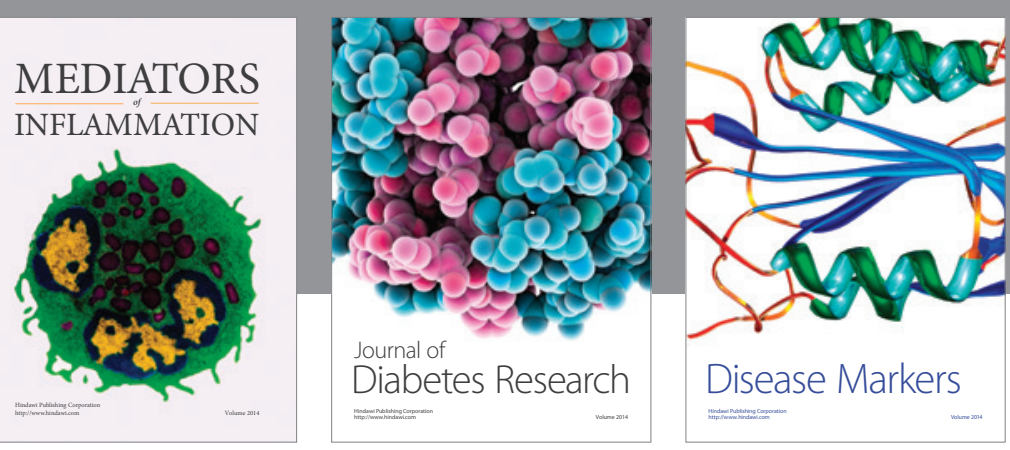

Disease Markers

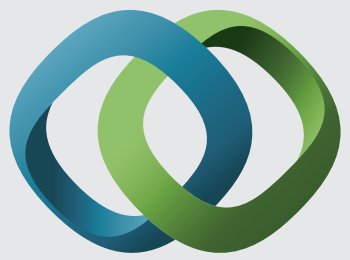

\section{Hindawi}

Submit your manuscripts at

https://www.hindawi.com
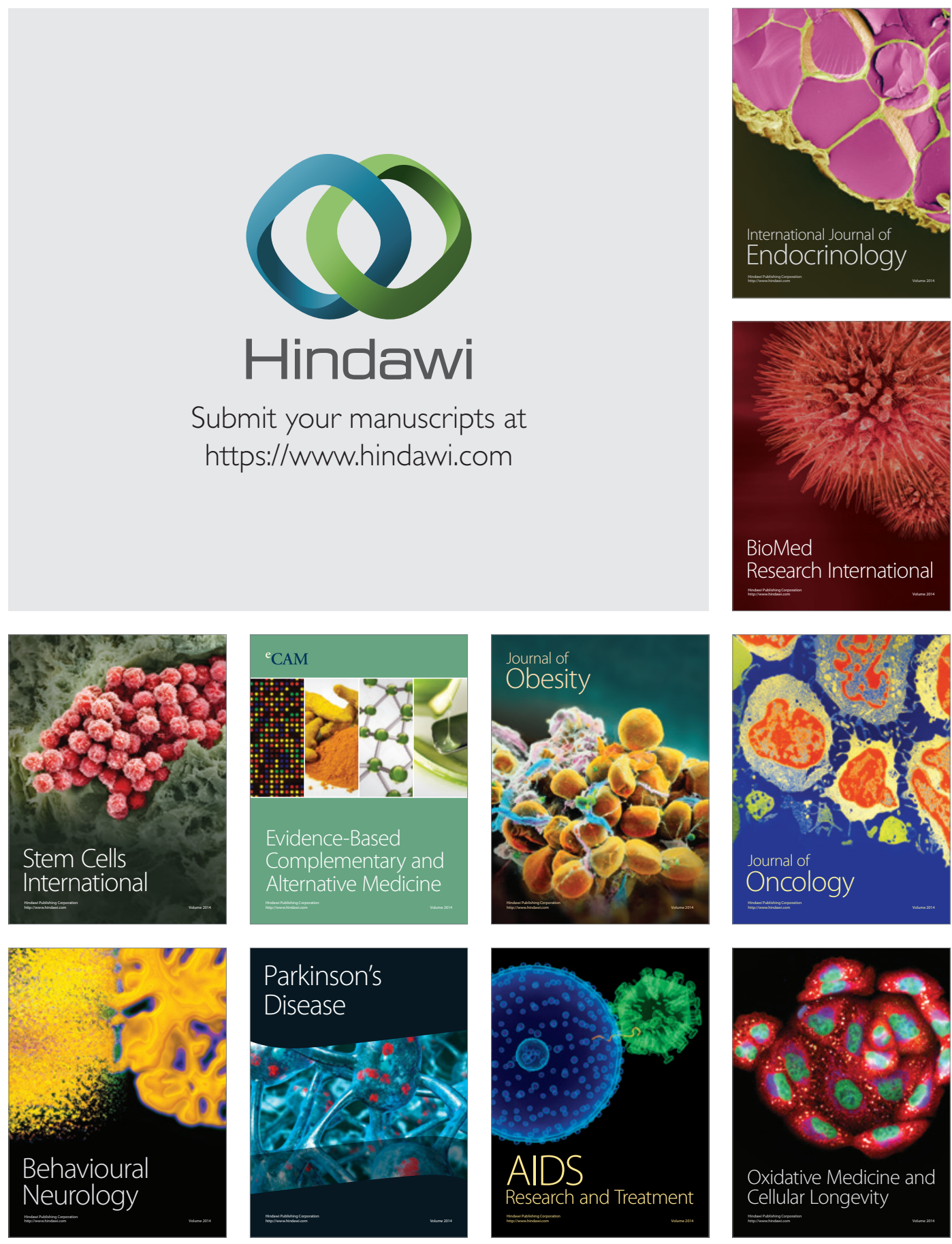